\title{
Design and Implementation of Comprehensive Anti- Electric Larceny Remote Online Monitoring System
}

\author{
Xie Shengli ${ }^{1}$, Zhou Guoliang ${ }^{1}$, Zhu Ying ${ }^{2}$, Wang Lizong ${ }^{3}$, Cang \\ Jing $^{3}$, Zhang Mengyuan ${ }^{3}$,Gao haichao ${ }^{3}$, Ma shengjiang ${ }^{3}$ \\ 1. Skill Training Center of the State Grid Jibei Electric Power Co. Ltd \\ 2. Sanhe Power Supply Branch of the State Grid Jibei Electric Power \\ Company Limited \\ ${ }^{3}$ Beijing Xinyuan Green Power Technology Co. Ltd.
}

\begin{abstract}
.
Aiming at the control line loss and anti electric larceny requirements faced by the electric power company, a comprehensive anti electric larceny remote online monitoring system has been developed. A special transformer electric remote inspection device based on the principle of the electric larceny is designed to detect the users' stealing electricity behavior, and communicate with the monitoring master station through GPRS. The outlier mining algorithm based on the density is used to screen the suspicious users from a wide range of users, and focus on tracking. Comprehensive anti-electric larceny remote online monitoring system adopts the three-layer system architecture, with the functions of remote inspection, real-time monitoring, abnormal power consumption analysis, and it effectively discovered and reduced the electric larceny behavior through the application in parts of the power companies.
\end{abstract}

Keywords: Remote inspection; Outlier mining; On-line monitoring; Anti- electric larceny

\section{Introduction}

The requirements of the grid companies for the refinement of enterprise management, especially the requirements for the line loss management are increased. The power supply enterprises which occur more than $70 \%$ line loss power are in the distribution network, especially are the users with the 10000 volt special transformers, because of its large consumption of electricity, the electric power loss is quite serious when the electric larceny behaviors and abnormal use of the electricity occur, which is always a difficulty for line loss management of power supply companies. In recent years, although, the negative control terminal is installed in the special transformer to conduct the remote meter reading for electric energy meter, it does not have the function of automatic analysis of 
abnormal power consumption, and has no monitoring and detection ability for various high-tech electric larcenies at present. On the other hand, in recent years, the North China areas are facing serious environmental problems of the haze. In order to protect environment, according to the relevant provisions, blackout processing was conducted for some enterprises and power companies with serious pollution, but some enterprises ignored state laws and regulations, they illegally produced a large number of PM2.5 pollutants, so the control of environment pollution also needs an online monitoring system, and timely detects the illegal production behaviors. Based on the above reasons, the development of an antelectric larceny system with the function of remote online monitoring has become the urgent demand for the electric power companies.

A special transformer electric remote inspection system is introduced in this paper, which can conduct all $7 * 24$ hour closed loop monitoring on the key users of special transformers. The automatic analysis of abnormal electricity consumption through the monitoring data has the function to obtain evidence of the electric larceny, and it can assist inspectors to seize various forms of high-tech electric larceny, improve pertinence and efficiency of the loss reduction work, rapidly lock the specific factors leading to a high line loss, and quickly reduce the line loss management. So it is an effective way to solve the current line loss management dilemma of the special transformers.

\section{Research Status at Home and Abroad}

In view of the dilemma of ineffectively control of the current 10000 volts special transformer line loss, in China, the power supply enterprises and relevant units have carries out a series of research and practical work of the monitoring and management of the special transformer line loss ${ }^{[1]}$, which plays a monitoring role in the process of electricity consumption to a certain extent.

The current common methods of electric larceny are as follows:

Electric larceny with a strong magnet. With the popularization and application of multifunction electricity meter, there are more and more means of electric larceny aiming at the multi-function electricity meter. In which, the universal means is to use a strong magnet for electric larceny. The size of the electric larceny device is a cigarette box, it does not alter any connection, and it can affect the normal measuring of the electricity meter, still the meter detection shows normal. The basic principle of the electric larceny with a strong magnet is as follows: use a strong magnet to make CT saturation in the electricity meter; leading to the two output does not vary with the linear load changes. The means of electric larceny has the advantages of simple operation, low cost, strong concealment, and its loss of electricity is about $10 \% \sim 90 \%$.

Electric larceny by means of current loop. There are mainly two categories for the current loop, respectively, the current loop for "open circuit" and the current loop for "loop circuit". It is easy to detect the current open circuit, and it is difficult to detect the current loop circuit.

Electric larceny by means of voltage circuit. Electric larceny by means of voltage circuit deliberately changes the normal connection of the electricity 
metering voltage circuit by various means, or intentionally causes the breakdown of measuring voltage circuit, resulting in the pressure loss of the electric voltage coil or the reduction of pressure, so as to achieve the purpose of less power measuring, this method is also called electric larceny with under voltage.

Electric larceny by means of phase shifting.This method deliberately changes the normal connection of electric energy meter by various means, or gets access to the voltage and current which have nothing to do with the coils of the electric energy meter; and some also use the specific connection method of the inductance or capacitance, so as to change the normal phase relationship between voltage and current in the coils of the electric energy meter, resulting in slow turn and even reverse turn of the electric energy meter.

Deliberately changes the normal connection of electric energy meter by various means, or gets access to the voltage and current which have nothing to do with the coils in the electric energy meter; and some also use the specific connection method of the inductance or capacitance, so as to change the normal phase relationship between voltage and current in the coils of the electric energy meter, resulting in slow turn and even reverse turn of the electric energy meter.

To strengthen the management of measurement equipment can monitor the electric larceny behaviors to a certain extent. So we can use a special metering box or the pry proof seal, select the electric energy meter with the function of anti electric larceny, seal the conductor from the low-voltage outlet end of transformer to the metering device, install a special metering cabinet metering panel and a distribution transformer with the function of anti electric larceny, reasonably select the multiplying power of current transformer metering device ${ }^{[2-3]}$.

With the popularity of the electric energy data acquisition system, timing acquisition of the power, voltage, current, power , and other data can be carried out through remote meter reading, load control terminal , the network table , etc., and the data can be analyzed to determine the normal or abnormal electricity consumption of the special transformer's users ${ }^{[4-5]}$.

A customized power monitor is used to monitor the operation status of the users' metering equipment, and its principle is as follows: the wireless current transducers are respectively installed in the input end of the power transformer high voltage power line, the output end of the low voltage power line and the outlet end of the users, and then the source generated by the wireless current transmitter is used to conduct the amplified monitoring on the current signal, the temperature on the nodes of the line ${ }^{[6]}$. And it sends the signals to the GSM/GPRS remote monitoring terminal through the micro power wireless current transmitter; the remote monitoring terminal can quantify wireless signal from the power transformer high-low port, then conduct the contrast calculation, and the primary-side and the secondary-side apparent power of the current power transformer can be obtained, so the purpose of electric larceny monitoring is achieved $^{[7]}$.

The above methods are mostly to improve or monitor in the aspect of anti electric larceny, the 24- hour closed loop monitoring technology and equipment to compare the high and low pressure data is not yet used. 


\section{Principles of the System}

Electric remote inspection device of the special transformer. The normal electricity criterion of the special transformer is ${ }^{[8]}$ :

$$
0 \leq \frac{n\left(i_{A}+i_{B}+i_{C}\right)}{i_{a}+i_{b}+i_{c}}-1 \leq m
$$

Wherein, $I$ indicates three-phase inflow and outflow current, $n$ indicates the ratio of the special transformer, $M$ is the value set by the users, indicating the loss. The primary-side and the secondary-side electricity information data of the transformers are gathered and contrasted to determine the users' consumption behaviors.

Based on the above principle, it is needed to develop a remote inspection device installed on the side of the special transformer to gather current data of the input and output. The device is composed of the data recorder, high pressure wireless detection unit, the current acquisition device of the electricity meter, a smart wiring harness, special installation tools and a dedicated portable box, in which, the high pressure wireless detection unit can realize the electric loading and unloading.

It is designed from the three aspects of monitoring the load of the users' $10 \mathrm{kv}$ incoming line, the internal parameters of the meter and the electromagnetic field strength of the meter box. Its core functions are as follows: to measure actual load of users, to conduct the remote diagnostics of the means of electric larceny, to locate the electric larceny and to achieve accurate conviction of the electric larceny behaviors. The installation and wiring layout of remote inspection device of the special transformer electricity meter is shown in Figure 1 :

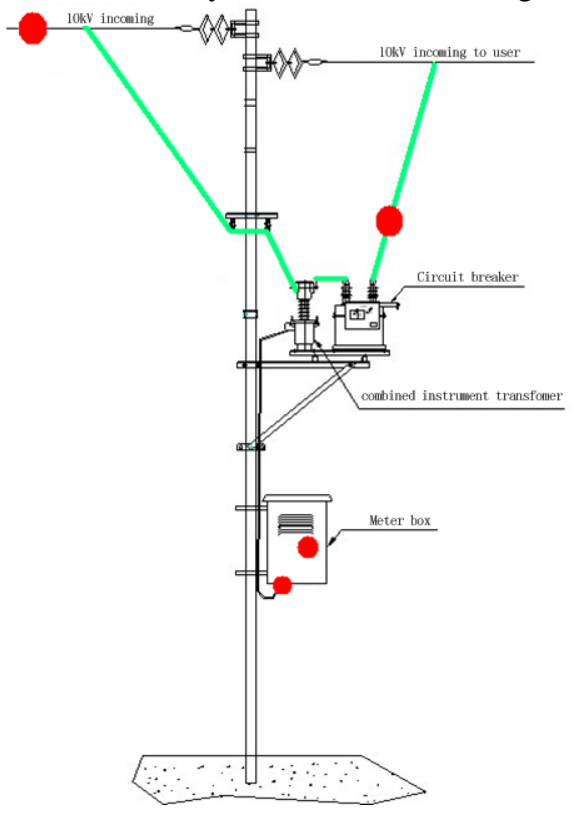


Fig 1 the remote inspection device of the special transformer electricity meter Outlier mining of the suspicious electric larceny users. The data acquired by the electric remote inspection device of the special transformer are the time series data with a certain frequency, the data of each terminal can take the latest data acquired at $\mathrm{m}$ points, the data of $\mathrm{N}$ terminal can form a data matrix with $\mathrm{m}$ rows and n columns. And each column is regarded as a data item, at this column, m data can be regarded as a property value of $\mathrm{m}$ at this monitoring point; the outlier mining algorithm is used to find some points with the feature inconsistent with most of the points, and these data are taken as a potential electric larceny user for the key monitoring ${ }^{[9-10]}$. The use of the outlier mining algorithm is described as follows:

Firstly, for a specified adjacent number (k), based on the density of the adjacent calculated object $(\mathrm{x}, \mathrm{k})$, the formula used is as follows:

$$
\operatorname{density}(x, k)=\max \{\|x-k\|\}
$$

And thus the outlier score of each object is calculated; and then the adjacent average density calculation of the point is calculated; the average relative density of the point is calculated by using them. This quantity indicates whether the $\mathrm{X}$ is in the neighborhood which is more densely populated or sparser than its neighbor, and it is taken as the outlier score of X. According to the outlier score, the outlier users are found s and specially monitored.

\section{System Design and Application Effect}

The system structure. Comprehensive anti-electric larceny remote online monitoring system realizes data acquisition through the special transformer electric remote inspection device, the special transformer electric remote inspection device is directly responsible for the setting of the terminal parameters and requirements of the task; the data collected from the terminal conducts the real-time communication through the special transformer electric remote inspection device, and the data are written into the database server, the special transformer electric remote inspection device realized the 24-hour unattended work. Even in the case of abnormal occurrence, once it is power off, the special transformer electric remote inspection device will automatically run electricity remote inspection device software after the re-start, and the terminal will automatically search for special transformer electric remote inspection device (on-line), and supplement measurement for the data. There may be multiple special transformer electric remote inspection devices, according to users' needs; it is quite often to equip two sets of special transformer electric remote inspection devices in a substation. The operation of the special transformer electric remote inspection device is realized mainly through the workstations, the negative load control software is installed in the workstation, parameters are issued by the operator, and the terminal is deployed and controlled and the data can be inquired. The topological structure of the network has the following characteristics:

1)Hot standby 
It is to ensure the continuous work of the load management system and ensure the integrity and not loss of the data. It also can also make the data not be lost even in abnormal failure caused by the system crashes and the wrong operation and management.

In practical application, the software of the host detects mutual operation through redundancy beckoning detection circuit, the complex monitoring procedures, logic judgments. If a host has confirmed the other's fault, then host will take over the fault operating procedures set based on various fault tolerance models in addition to the normal original task, and conduct the subsequent application and service.

2)Dual network redundancy

It is to ensure the reliability of network communication; a dual network communication mode is used. Two hosts have two cards each; one is the main card and the other is the backup, when the main card fails, the backup card takes over the communication of the main card. At the same time, the double network cards are respectively connected to different network segments. On one hand, it can reduce the network load, improve the network efficiency, on the other hand, it can ensure the security of data communication.

3)Information sharing between the main station and the sub station

The main station and the substation communicate according to the 476-92 statute, and realize the information sending at the main station $230 \mathrm{M}$ terminal users and the reporting of important users' information of the substation.

Application Effect. Comprehensive anti-electric larceny remote online monitoring system has abundant functions, they specifically include:

Remote inspection, which is used for the users who installed the high voltage detecting unit, it conducts the real-time monitoring whether there is fraudulent use of electricity;

Abnormal electricity consumption, which screens the suspicious users from the historical data;

Load analysis, which visually checks historical data of the users who installed the high pressure detection unit in the form of curve;

Curve data query, which is to inquire the current (primary, secondary, before the meter), voltage, power, power factor and other historical data, which provides reference history data for screening abnormal users;

Query of data analysis, which is to analyze the electric larceny from the historical data.

System management is to manage the user rights.

The operation interface of the system is shown in Figure 2-4. 


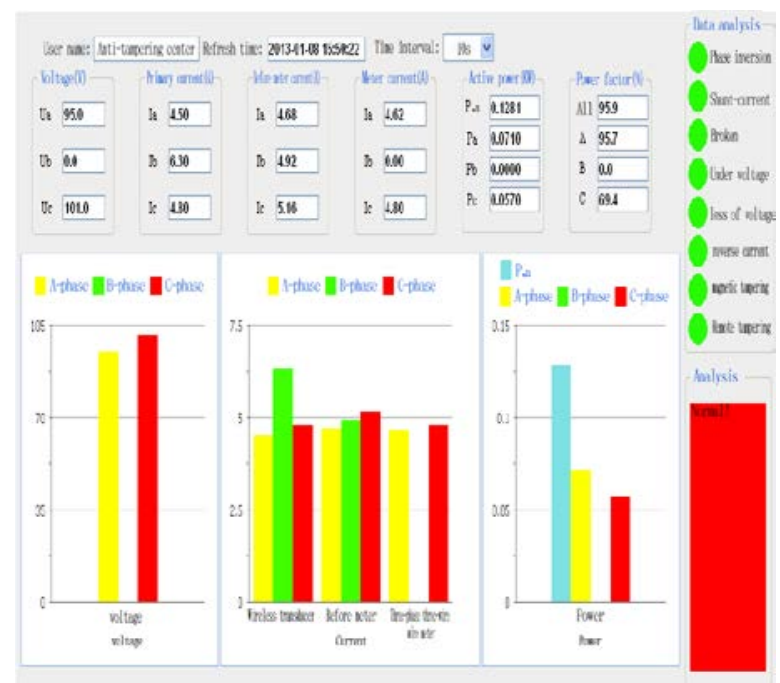

Fig 2 Remote diagnosis

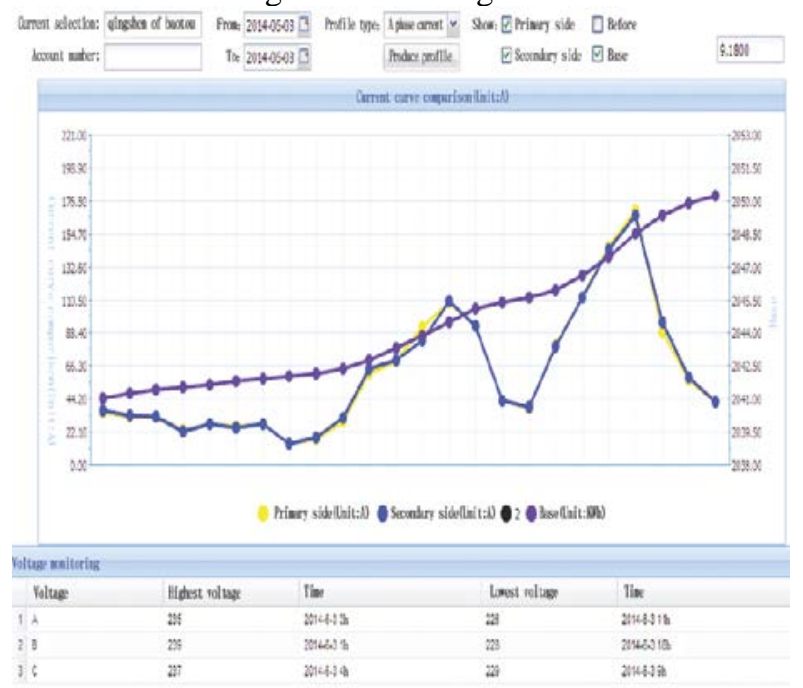

Fig 3 Negative load curve 


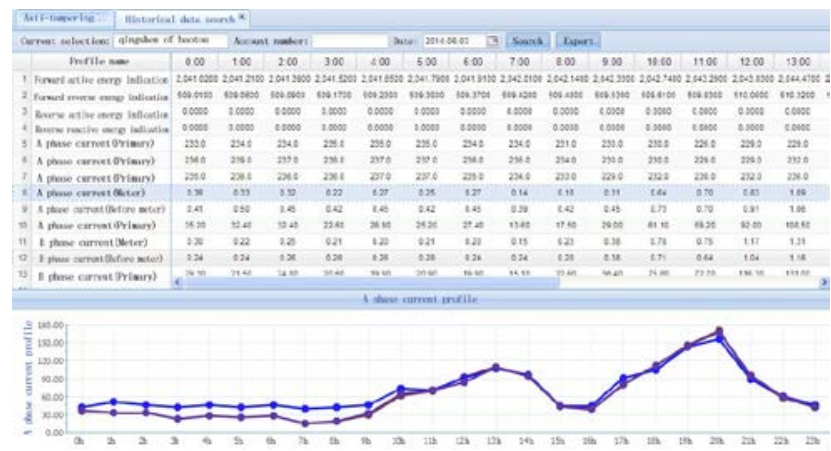

Fig 4 Monitoring data

\section{Conclusions}

Since the integration of human resources, finance, materials; and the system of big planning, big construction, big operation, big maintenance, big marketing put forward by the State Grid Company, the State Grid Company has paid more attention to the work of the electric larceny. Some energy-intensive enterprise users which lack integrity risk to conduct the electric larceny in order to reduce production costs at any cost; and they are more and more secluded, more and more have the ability of anti-reconnaissance. In view of the growing high-tech electric larceny, we continuously strengthen the development and innovation of the anti-electric larceny, and have obtained a series of achievements. Comprehensive anti-electric larceny online monitoring system is a practical technology, it not only has applied for a related patent, and has seized the special transformer users' electric larceny with the worth of 100 million yuan in the Sanhe Power Supply Branch of the State Grid Jibei Electric Power Company Limited; seized large electric larceny with the worth of 100 million in the Tianjin Electric Power Company. Currently, it has played an important role in more cities, to restore the huge economic loss for the state grid.

With the continuous deterioration of the haze in the regions of Beijing, Tianjin, and Hebei, it has become a normal state to restrict and halt the production of some enterprises with high pollution, and some enterprises re-produce through the electric larceny, which has put forward a higher request to the monitoring of the electric power companies. The design and development of the comprehensive anti electric larceny remote online monitoring system is introduced in this paper, it is believed that the technology can effectively achieve the electricity monitoring of the enterprises with high pollution and high energy-consumption, which can help the environment optimization.

\section{References:}

[1] Han Songlin, Function Analysis of Several Anti Stealing Electric Circuit [J]. Electrical Measurement \& Instrumentation, 1999, 36 (403): 8-9. 
[2] Li Jingshu. The Technical Measures Against Stealing Electricity [J]. Rural Electrician, 2000, (8): 20-21

[3] Yang Lan. Realization of Anti Electricity Stealing Function of the Distribution Management System [J]. Electric Power Automation Equipment, 2002,22 (1): $84-85$

[4] Chen Tengfei, Yang Mingyu, Hou Ruipeng. Development and Application of New Electricity Stealing Online Inspection System [J]. Inner Mongolia Electric Power Technology, 2012,30 (4): 95-99.

[5] Liang Houle, Liu Licheng. Development of the Anti -Electricity Stealing System Based on Electric Information Data Acquisition [J]. Information Systems Engineering. 2011, (11): 125-127

[6] Sun Fengjie, Liu Zhengfang, Zhang Yongcan. Anti- Electricity Stealing System Based on GPRS Wireless Transmission [J]. Power System Communication.2007,28 (171): 53-56

[7] Zhou Mo, Zhu Ruide, Wang Jinquan. Discussion on the Anti Electricity Stealing Real-time Monitoring System Scheme based on GSM Network [J]. Electric Power Automation Equipment, 2004, 24 (2): 64- 66

[8] Zhang Guichun. Analysis of Electricity Stealing Technology and Anti stealing electricity Measures [J]. Journal of Shenyang Institute of Engineering (NATURAL SCIENCE EDITION), 2010, (3): 235-237.

[9] Yang Huayun, Jiang Bo, Jiang Wei, et al. The All-digital Electrical Energy Metering System Based on Optical Current and Voltage Transducer[A].Asia-Pacific Power and Energy Engineering Conference [C]. IEEE, 2010

[10] Li Yongjun, Xu Xiaorong. Design and Implementation of the Minitype ElectricEnergy Meter Field Calibrator Based on MCP3906[A]. Industrial Control and Electronics Engineering[C]. IEEE Computer Society, 2012: $1173-1176$ 